\title{
PLÂNCTON DOS TANQUES DA ESTAÇÃO DE PISCICULTURA DA UNIVERSIDADE FEDERAL DE SANTA MARIA, RS, BRASIL
}

\author{
Geraldo Salgado Neto e José Augusto Teston \\ Curso de Biologia - Centro de Ciências Naturais e Exatas \\ UFSM - Santa Maria, RS \\ João Fernando Prado \\ Departamento de Biologia - Centro de Ciências Naturais e Exatas \\ UFSM - Santa Maria, RS
}

\section{RESUMO}

Com o objetivo de selecionar algas Chlorophyta para cultura em laboratorio. numa etapa futura, foi realizado o levantamento do plâncton nos tanques da Estação de Piscicultura da Universidade Federal de Santa Maria. No momento, é apresentada a relaçào dos gèneros pertencentes ao fitoplâncton (37) e ao zooplâncton (23) identificados na análise de cinco amostras coletadas nos meses de abril, junho e agosto de 1994.

Palvras-chaves: Fitoplâncton, Zooplâncton, Piscicultura

\section{SUMMARY}

This work has as objective to present the results of five samples analises of plancton collected on April, June and August in 1994, in the Pisciculture Station tanks of University of Santa Maria, where were identified 37 genera belonging to Phytoplanctum and 23 to Zooplanctum. Later some species of Chlorophyta will be selected and identified for laboratory growing. 


\section{INTRODUÇÃO}

O plâncton desempenha papel fundamental na cadeia alimentar dos peixes em todos os ambientes aquáticos, sendo o fitoplâncton, alem de produtor primário, importante fonte de alimento, juntamente com os constituintes de zooplàncton. Economicamente, os constituintes do plâncton vêem sendo utilizados na piscicultura como fonte de alimento para pós-larvas de peixes e alevinos

Nas estações de criação de peixe, um dos grandes problemas relacionados com a produção de alevinos é a sua alimentação, tendo em vista o reduzido tamanho da boca das póslarvas de peixes, uma vez que a granulometria das rações não é, muitas vezes, adequada. A utilizaçào de culturas de plâncton, visando a alimentação de pós-larvas de peixes e alevinos, vem sendo cada vez mais empregada nas estações de piscicultura de todo o mundo (Brandão; ćmunicação pessoal; Professor do Departamento de Zootecnia/UFSM).

Este trabalho tem como objetivo a contribuição ao conhecimento do plâncton que ocorre nos tanques da Estação de Piscicultura da Universidade Federal de Santa Maria, apresentando a relação dos gêneros pertencentes ao fito e ao zooplâncton. Os resultados obtidos servirào de base para a etapa seguinte, que consistirá na determinação e na seleção de espécies de Chlorophyta para a cultura em laboratório, visando a alimentação de pós-larvas de peixes e alevinos.

\section{A ESTACÃO DE PISCICULTURA DA UFSM}

A Estação de Piscicultura da Universidade Federal de Santa Maria (fig. 1) iniciou suas atividades no ano de 1970 e compreende 12 tanques (fig. 2) de formato retangular, com medidas de $20 \mathrm{mX} 50 \mathrm{~m}$ e profundidade variando entre $1 \mathrm{~m}$ e $1,5 \mathrm{~m}$. Os tanques estão construídos sobre solo areno-argiloso, depositando-se no fundo uma vasa constituida por matéria orgânica em decomposição, originada dos tratamentos periódicos com adubação orgânica (esterco de animais), adubação inorgànica (fosfatos e NPK) e calagem (calcário ou cal apagada)

\section{MATERIAL E MÉTODOS}

As amostras foram obtidas por coletas com rede de plâncton com malha de $0,25 \mu \mathrm{m}$ de abertura, realizadas em 18 de abril, no tanque $3 ; 10$ de junho, no tanque $4 ; 17$ de junho, no tanque 7; 01 de agosto, tanque 6 e 30 de agosto no tanque 1 (Fig 2), todas no ano de 1994. As 
amostras, num total de cinco, foram acondicionadas em frascos etiquetados e levadas ao Laboratório de Botânica do Centro de Ciências Naturais e Exatas da Universidade Federal de Santa Maria.

\section{ESTACÃO DE PISCICULTURA DA UFSM}

fig. 1

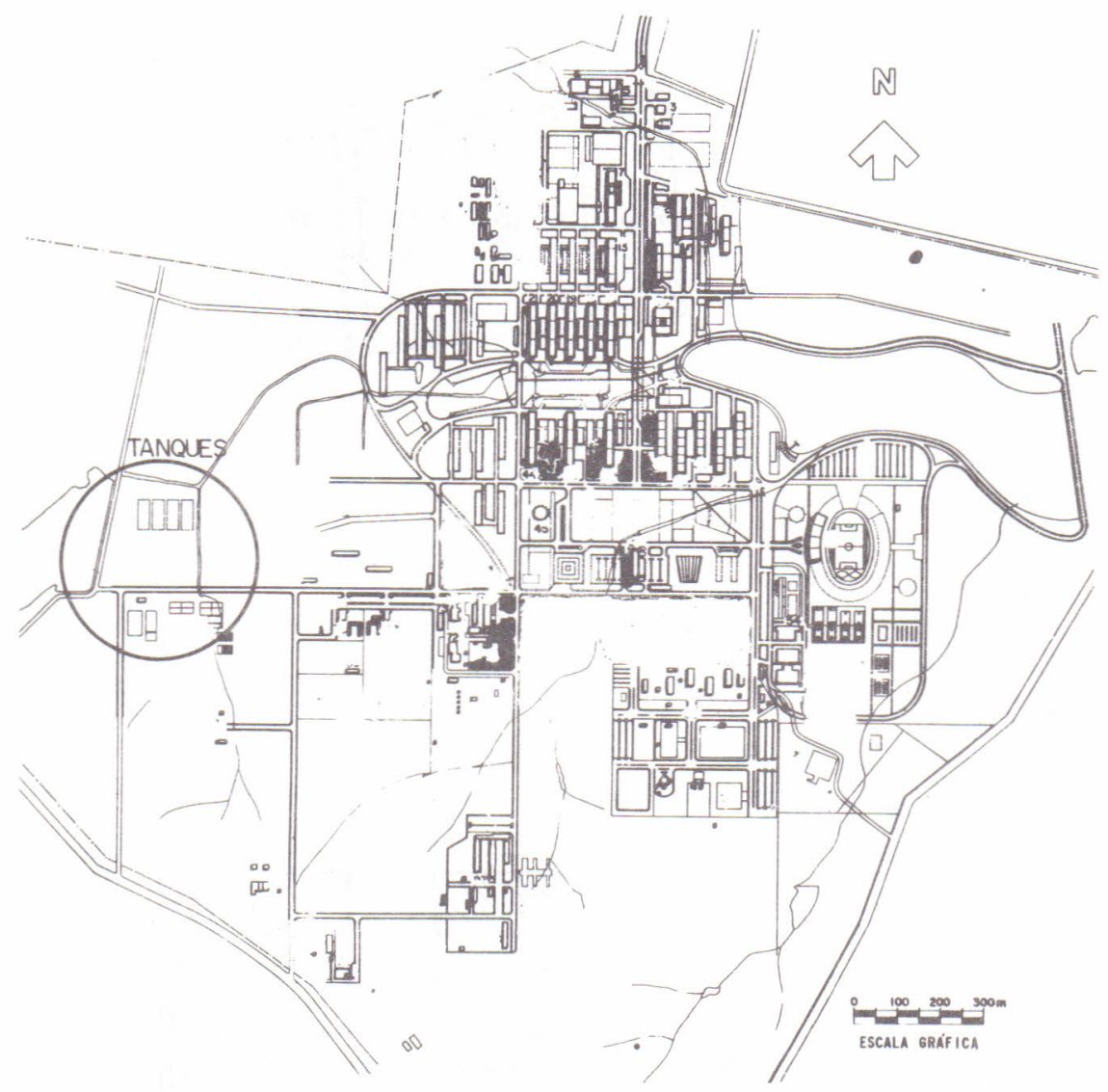

SITUAGATO 
TANQUES DA ESTAÇĀO DE PISCICULTURA DA UFSM

fig. 2
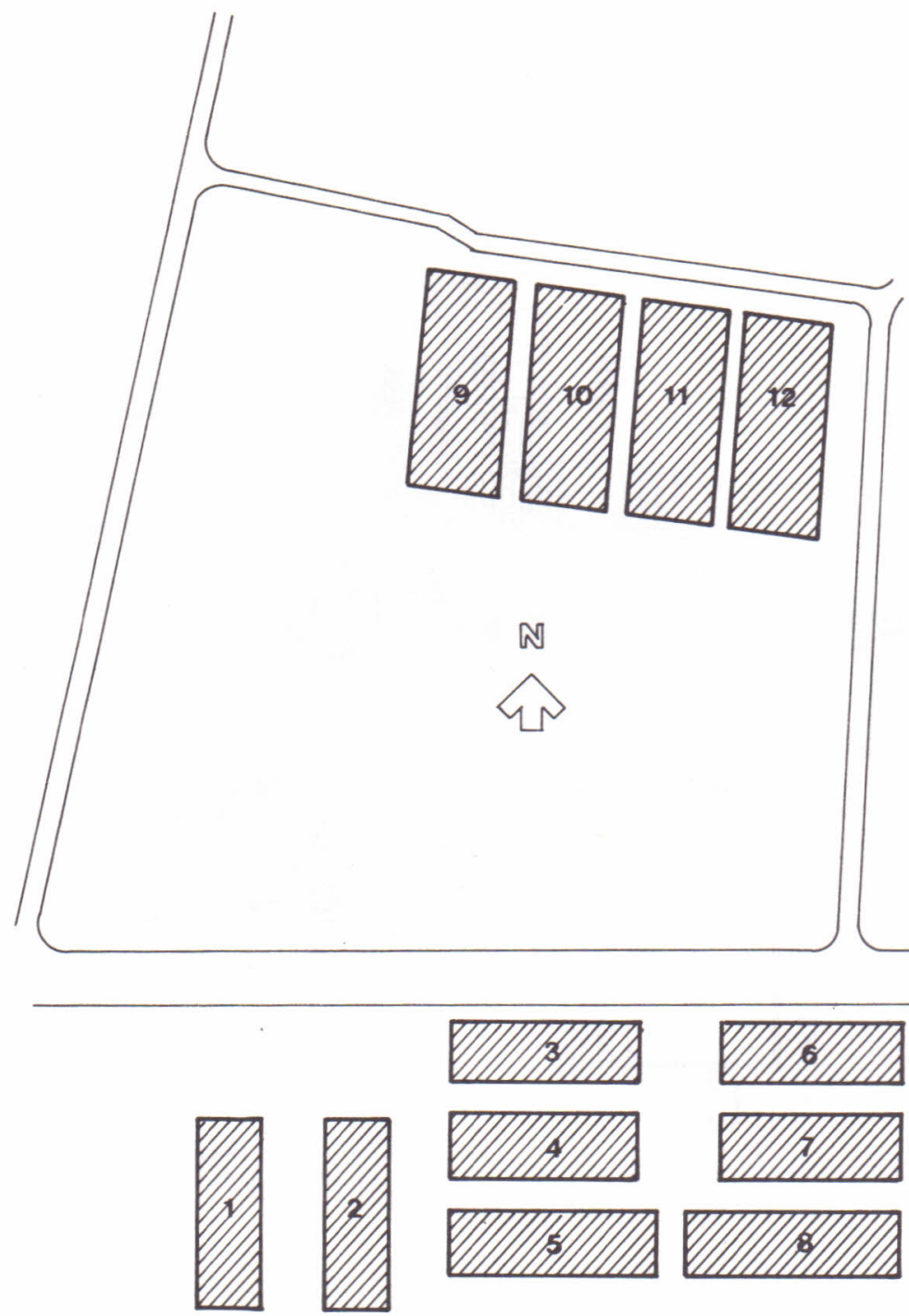
O material foi mantido sob refrigeração para posterior análise ao microscópio ótico. A determinação e a identificação dos gêneros pertencentes ao fitoplâncton foram feitas com base nos seguintes autores: Bicudo, 1970 e Streble \& Krauter, 1987; para os pertencentes ao zooplâncton os autores utilizados foram Barnes, 1990 e Streble \& Krauter, 1987. Os gêneros do fitoplâncton foram ordenados taxonomicamente de acordo com Round, 1983 e os do zooplâncton, de acordo com Barnes, 1990.

\section{RESULTADOS E DISCUSSÃo}

Foi identificado um total de 60 gêneros, sendo 37 pertencentes ao fitoplâncton e 23 ao zooplâncton, estando relacionados, taxonomicamente, como segue:

\section{FITOPLÂNCTON}

Cyanophyta

Chroococcus

Merismopaedia

Anabaena

Oscillatoria

Bacillariophyta

Asterionella

Fragilaria

Eunotia

Navicula

Pinnularia

Chlorophyta

Chlamydomonas

Eudorina

Gonium

Volvox

Ankistrodesmus

Botryococcus

Chlorella

Dictyosphaerium

\section{ZOOPLÂNCTON}

Protozoa

Peranema

Amoeba**

Arsslla

Difflugia

Paramaecium

Stentor

Vorticella**

Aschelminthes (Rotifera)

Brachionus

Koelatella

Notommata

Philodiıa

Rucaria

Nematoda

Monhystera

Annelida

Aeolosoma

Stylaria

Artropoda 
Pediastrum

Scenedesmus

Ulotrix*

Bulbochaete*

Oedogonium*

Netrium

Arthrodesmus

Closterium

Cosmarium

Desmidium*

Bambusina*

Micrasterias

Penium

Pleurotaenium

Staurastrum

Mougeotia*

Spirogyra*

Zygnema*

Euglenophyta

Euglena

Phacus

\section{Crustacea}

Daphnia

Moina

Bosmina

Sida

Cyclops

Macrocyclops

Insecta

Anopheles**

Culex**

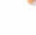


alguns insetos aquáticos podem ser, no plâncton, encontradas, o mesmo acontecendo com larvas de certos moluscos e, também, com algumas algas. Também a fase larval de muitos peixes poderá ser considerada como plâncton acidental.

Os gêneros pertencentes ao plâncton acidental são considerados no presente trabalho, devido a sua importância na cadeia alimentar nos ambientes aquáticos.

\section{CONSIDERAÇÕES FINAIS}

A análise das amostras revelou um material bastante rico de fito e zooplâncton, dando, dessa maneira, base para futuros trabalhos de enfoques diversos, como estudos de taxonomia e de cunho ecológico. Como já mencionado, desse levantamento serão selecionadas espécies de Chlorophyta para cultura em laboratório, etapa já em implantação, visando a aplicação na piscicultura como ração para pós-larvas de peixes e alevinos.

\section{AGARDECIMENTOS}

Os autores agradecem ao Desenhista Paulo Roberto Prado pela confecção dos mapas à nanquim e à Tradutora Carmen Lidia Prado pela versão do resumo para o Inglês.

\section{BIBLIOGRAFIA}

1.BARNES, R. D. Zoologia dos Invertebrados. $4^{\text {a }}$ edição. Roca, 1990. São Paulo. 1179 p.

2. BICUDO, C. E. M; Bicudo, R. M. T. Algas de Águas Continentais Brasileiras. FUNBEC. São Paulo, 1970. 228p.

3. KLEEREKOPER, H. Introdução ao Estudo da Limnologia. Ed. da Universidade Federal do Rio Grande do Sul. $2^{\text {a }}$ ed. 1990. 329p.

4. ROUND, F. B. Biologia das Algas. Ed. Guanabara Dois, $2^{a}$ ed. Rio de Janeiro, 1983. 263p.

5. StREBLE, H.; KRAUTER, D. Atlas de Los Microorganismos de Agua Dulce. Ed. Omega Barcelona, 1987. 337p. 
